\title{
Chloride in Heart Failure Syndrome: Its Pathophysiologic Role and Therapeutic Implication
}

Hajime Kataoka

Received: May 10, 2021 / Published online: August 14, 2021

(C) The Author(s) 2021

\begin{abstract}
Until recently, most studies of heart failure (HF) focused on body fluid dynamics through control of the sodium and water balance in the body. Chloride has remained largely ignored in the medical literature, and in clinical practice, chloride is generally considered as an afterthought to the better-known electrolytes of sodium and potassium. In recent years, however, the important role of chloride in the distribution of body fluid has emerged in the field of HF pathophysiology. Investigation of $\mathrm{HF}$ pathophysiology according to the dynamics of serum chloride is rational considering that chloride is an established key electrolyte for tubulo-glomerular feedback in the kidney and a
\end{abstract}

possible regulatory electrolyte for body fluid distribution. The present review provides a historical overview of HF pathophysiology, followed by descriptions of the recent attention to the electrolyte chloride in the cardiovascular field, the known role of chloride in the human body, and recent new findings regarding the role of chloride leading to the proposed 'chloride theory' hypothesis in HF pathophysiology. Next, vascular and organ congestion in HF is discussed, and finally, a new classification and potential therapeutic strategy are proposed according to the 'chloride theory'.

Keywords: Body fluid; Chloride; Chloride theory; Diuretics; Heart failure; Renin-angiotensin-aldosterone system 


\section{Key Summary Points}

Chloride $(\mathrm{Cl})$ has recently been recognized to have an important role in heart failure (HF) pathophysiology, including prognostic marker and central role for regulation of body fluid status.

The investigation of HF pathophysiology according to $\mathrm{Cl}$ dynamics is rational because $\mathrm{Cl}$ is a key electrolyte for the renin-angiotensin-aldosterone system in the kidney and possible regulatory electrolyte for body fluid distribution.

Firstly, this review article begins with a historical overview of the evolution of HF pathophysiology, including recent attention to the $\mathrm{Cl}$ as an important prognostic marker in cardio-vascular disease.

Then, known physiologic roles and recent findings regarding the $\mathrm{Cl}$ in $\mathrm{HF}$ pathophysiology will be discussed, including a proposal for 'chloride theory'.

Thirdly, the mechanism(s) of the regulation of water distribution by $\mathrm{Cl}$ and clinical meanings of vascular and organ congestions in HF will be discussed.

Finally, a new classification of diuretics and therapeutic strategy for their use will be described for specifically treating different distributions of congestion, e.g., intravascular and interstitial spaces, according to the 'chloride theory' for HF pathophysiology.

The 'chloride theory' of HF pathophysiology, which states that "changes in serum chloride concentration positively correlate with the changes in plasma volume", would provide valuable and rational strategies for understanding and treatment of HF.

\section{INTRODUCTION}

Until recently, most studies of heart failure (HF) syndrome have focused on body fluid dynamics [1-3] through control of the sodium, potassium, and water balance in the body $[4,5]$. An established hypothesis of body fluid regulation in health and disease, including HF, is that the arterial circulation is the primary body fluid compartment modulating renal sodium and water excretion [6-9]. Despite the abundant literature on HF pathophysiology, chloride was not included as an investigational target until recent years. Since 2015, the important role of chloride has begun to be recognized in the field of HF pathophysiology, including as a clinically significant prognostic marker [10-14] and a regulatory electrolyte for body fluid distribution [15-19]. Investigation of HF pathophysiology according to the dynamics of serum chloride is rational considering that chloride is an established key electrolyte for tubulo-glomerular feedback in the kidney [20-22] and a possible regulatory electrolyte for fluid distribution in the human body [15-19].

This review article begins with a historical overview of HF pathophysiology, followed by descriptions of the recent attention to the electrolyte chloride in the cardiovascular field, the known role of chloride in the human body, and recent new findings regarding the role of chloride leading to the 'chloride theory' hypothesis in HF pathophysiology. Vascular and organ congestion in HF is then discussed, and a new classification and potential therapeutic strategy is proposed for specifically treating different distributions of congestion, e.g., intravascular and interstitial spaces, according to the 'chloride theory'. This article is based on previously conducted studies and does not include any new data obtained from human participants or animals. 


\section{HISTORICAL OVERVIEW AND ATTENTION TO CHLORIDE IN HF PATHOPHYSIOLOGY}

\section{Hemodynamic Era of HF Syndrome}

Congestive HF is a 'pathologic condition in which the heart cannot pump enough blood to meet the body's needs' or an 'abnormality of cardiac structure or function leading to failure of the heart to deliver oxygen at a rate commensurate with the requirements of the metabolizing tissues' [23]. On the basis of available devices to measure blood flow, blood pressure, and blood volume in the last half of the 20th century, congestive HF was defined as mainly a hemodynamic disorder [23-26]. Although abnormal hemodynamics may account for some of the symptoms of HF, HF progression cannot be explained by these factors alone $[26,27]$. Current therapeutic options to increase cardiac power improve the hemodynamic status of HF patients, but the longterm outcome may be adversely affected [26].

\section{Neurohormonal Era of HF Syndrome}

More recent studies have revealed numerous metabolic and neurohormonal abnormalities in $\mathrm{HF}$, in addition to the hemodynamic abnormalities, suggesting that HF progresses through dysfunction of the sympathetic nervous system $[2,28]$, the renin-angiotensin-aldosterone system (RAAS) [6-9], the antidiuretic hormone (ADH; or arginine vasopressin hormone) axis $[6-9,29,30]$, and vasodilatory/natriuretic pathways [31]. The importance of pharmacologic modulation of neurohormonal abnormalities and the resulting favorable effects on the prognosis of HF patients [32, 33] have confirmed the crucial involvement of the neurohormonal system in HF pathophysiology. According to the 2016 European Society of Cardiology Guidelines [34], HF represents a complex clinical syndrome characterized by cardiac function and neurohormonal regulation abnormalities, manifesting as effort intolerance and fluid retention, and resulting in reduced longevity. Thus, in HF pathophysiology, a unifying principle of body fluid regulation is critical, not only for understanding how to maintain the integrity of the arterial circulation system but also for managing the interactions of various neurohormonal afferent and efferent mechanisms [6-9] regulating body fluid volume by modulating sodium and water reabsorption in the kidney. While plasma volume expansion has long been considered a classical feature of worsening $\mathrm{HF}[9,35,36]$, the biochemical underpinnings of fluid distribution in $\mathrm{HF}$ are not yet clarified.

\section{Recent Attention to Chloride in HF Syndrome}

Chloride, despite flanking sodium as its anionic counterpart in salt, has remained largely ignored in the field of HF pathophysiology, presenting in the medical literature and in clinical practice as an afterthought to the more popular electrolytes sodium and potassium, or simply as a substitute for bicarbonate to preserve electroneutrality [37, 38]. Searching for the term 'hyponatremia' in Medline results in more than 11,000 citations, whereas searching for 'hypochloremia' results in only 290 citations [14]. The majority of published HF studies have not collected serum chloride levels [14]. Recently, hypochloremia has begun to be recognized as an important prognostic marker.

\section{PROGNOSTIC MARKER OF HYPOCHLOREMIA IN CARDIO- VASCULAR DISEASE}

In a Belgian general population cohort $(n=9106)$ followed up for 10 years, a serum chloride concentration lower than $100 \mathrm{mEq} / \mathrm{l}$ was associated with a $48 \%$ higher risk of allcause mortality after adjustment of age, body mass index, and serum sodium levels [39]. Recently, McCallum et al. [40], analyzing 12,968 hypertensive individuals with a 35 -year follow-up, reported that the lowest quintile of serum chloride concentration $(<100 \mathrm{mEq} / \mathrm{l})$ was associated with a $20 \%$ higher mortality (allcause, cardiovascular, and non-cardiovascular) 
compared with the remainder of the subjects; a $1 \mathrm{mEq} / \mathrm{l}$ increase in serum chloride was associated with a $1.5 \%$ reduction in all-cause mortality after adjustment for baseline confounding variables as well aa sodium, potassium, and $\mathrm{HCO}_{3}{ }^{-}$levels.

In the field of HF epidemiology, Felker et al. [41] listed in the tables of their published manuscript serum chloride as the leading laboratory parameter and statistically stronger parameter (hazard ratios 0.78; Chi-square 31.8) than serum sodium (hazard ratios 1.14; Chisquare 8.18 ) in a final multivariable model for all-cause mortality. No more mention on the clinical significance of chloride was made in this report, however, presumably because assessment of chloride was outside the scope of this study. In 2015 and 2016, Grodin et al. $[10,11]$ reported that the serum chloride concentration, but not the serum sodium concentration, is an independent prognostic marker of HF. Immediately after this report, the same group re-confirmed that serum chloride is strongly and independently associated with worsened survival in patients with chronic HF and accounts for the majority of the risk otherwise attributable to hyponatremia defined by $\leq 96 \mathrm{mmol} / \mathrm{l}$ [14]. Demissei et al. [13] intended to create a clinical model by incorporating multi-marker and multi-time-point analysis of biomarkers for the prediction of postdischarge clinical outcomes in high-risk-acute HF patients. In their study, they identified serum chloride concentration as a clinically significant biomarker (other markers were blood urea nitrogen, interleukin-6, cTnl, sST-2, and VEGF-1) among a set of 48 circulating biomarkers. Many subsequent studies, except several studies [42, 43], confirmed hypochloremia, but not hyponatremia, as an important prognostic marker in HF status [44-46], although hypochloremia may not be a clinically relevant prognostic marker compared with other well-established prognostic variables (e.g., age, co-morbidities, and hemodynamic derangement, etc.) [42]. Malignant arrhythmic events might be involved in the poor prognosis of HF patients with hypochloremia [44]. The pathophysiologic role of chloride underlying HF pathophysiology, however, was not precisely examined in those reports. Then, what is the physiologic role of chloride in $\mathrm{HF}$ syndrome?

\section{PATHOPHYSIOLOGIC ROLE OF CHLORIDE IN HEART FAILURE}

\author{
Known Role of Chloride in the Human \\ Body Outside of HF Pathophysiology
}

The main source of chloride in the human is the intake of dietary sodium chloride (about 6-12 g, respectively $100-200 \mathrm{mmol} \mathrm{Cl}^{-}$) [47]. The majority of serum chloride filtrated into the nephrons is actively reabsorbed in the proximal convoluted tubules, and passively reabsorbed through the intercellular space along the electrochemical gradient in the tubules [48].

Chloride, indeed, has many physiologic roles in the human body. Major roles of chloride in the human body are briefly summarized as follows [37, 49-51]: (1) it is the most important extracellular anion, accounting for $97-98 \%$ of all strong anion charges and for two-thirds of all negative charges in the plasma, (2) it maintains serum electroneutrality, (3) it is the major extracellular strong ion and key electrolyte for maintenance of the acid-base balance, (4) it contributes to electrical activity in general (e.g., muscular and myocardial activities), (5) it contributes to hydrochloric acid $(\mathrm{HCl})$ production, maintenance of osmotic gradient, and fluid secretion in the gastrointestinal tract, (6) it affects oxygen transport and gas exchange, (7) it contributes to the maintenance of blood pressure and renal function, and (8) it contributes to the movement of water between fluid compartments. Details and well-constructed explanations of the physiologic roles of chloride outside of HF pathophysiology are described elsewhere [37, 49-51].

\section{Role of Chloride in Blood Pressure and 'Tubulo-Glomerular Feedback' Mechanism}

Outside of HF pathophysiology, the important role of chloride in the cardio-reno-vascular 
system was identified more than three decades ago-'chloride' is a crucial electrolyte that enables reabsorption of the filtered sodium from the urinary tubules into the extracellular body spaces, and maintains arterial pressure, independently from sodium [20, 40, 52, 53]. Many studies have also established that chloride, rather than sodium, plays a central role in the regulation of renin release from the juxtaglomerular apparatus (i.e., tubulo-glomerular feedback), i.e., renin secretion is inversely regulated by chloride concentration, namely the lower the chloride concentration, the higher the renin secretion, and vice versa [20-22]. Few studies to date, however, have investigated the crucial role of chloride in relation to $\mathrm{HF}$ pathophysiology.

\section{Discovery of Chloride for Body Fluid Distribution in HF Pathophysiology}

Chloride is a key osmolyte for the regulation of vascular [15, 17] and red blood cellular [19] fluid status under worsening or resolution of HF status in established HF patients. On the basis of the role of chloride in vascular/cellular volume regulation and its well-established central role in the regulation of RAAS activity in the kidney,

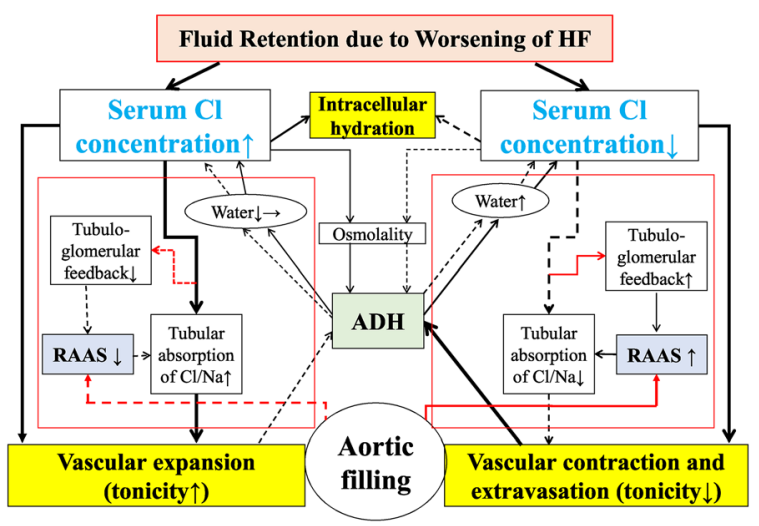

Fig. 1 The 'chloride theory' for explaining fluid dynamics in the course of worsening heart failure. The solid line indicates enhanced supply or excitatory effect, and the dotted line indicates reduced supply or inhibitory effect. The pathway of the RAAS, tubulo-glomerular feedback, and $\mathrm{ADH}$ in the kidney is outlined in red. $A D H$ antidiuretic hormone, $\mathrm{Cl}$ chloride, $\mathrm{HF}$ heart failure, $\mathrm{Na}$ sodium, RAAS renin-angiotensin-aldosterone system as well as in the maintenance of arterial pressure [20-22], the 'chloride theory', a unifying hypothesis for HF pathophysiology, was recently proposed $[16,18,54]$. This hypothesis is the first to unify the two main platforms of the body fluid-processing organs through one key electrolyte, chloride, in both (1) the kidney, which reabsorbs body fluid mainly under RAAScontrol [20-22], and (2) the body, an organ with dynamic storage of body fluid in the intracellular, intravascular, and interstitial compartments $[55,56]$. The 'chloride theory' for HF pathophysiology is briefly summarized in the following section.

\section{DEVELOPMENT OF THE 'CHLORIDE THEORY' FOR HF PATHOPHYSIOLOGY}

\section{General Consideration}

According to the 'chloride theory' for HF pathophysiology [18], two distinct modes of worsening $\mathrm{HF}$ progression are hypothesized, with different clinical characteristics according to the chloride accumulation pattern in relation to water retention, i.e., worsening HF with an increased (Fig. 1, left half) vs. non-increased serum chloride concentration (Fig. 1, right half) $[15,16,18]$. Each type of worsening HF might reflect differences in the RAAS and ADH activation and effectiveness, and the subsequent movement of serum electrolytes and water, in which body fluid is re-distributed to each body fluid compartment comprising extracellular (intravascular and interstitial spaces) and intracellular spaces. Additionally, the significant link between changes in the serum chloride concentration and hemodynamics is described $[16,57]$. Recent clinical data on the possible involvement of urinary chloride in the mechanism of 'tubulo-glomerular feedback' $[58,59]$ supports the concept of the 'chloride theory' of HF pathophysiology, but it is important to note that the 'tubulo-glomerular feedback' mechanism is greatly affected by the pharmacologic use of diuretics and neurohormonal blockades $[58,59]$. 


\section{Worsening HF with Increased Serum Chloride Concentrations}

In patients with worsening $\mathrm{HF}$ and an increase in the serum chloride concentration (Fig. 1, left half), the accumulation of serum chloride acts to maintain or increase intravascular volume, which places a greater burden on the failing heart. Maintaining the plasma volume might be beneficial for supplying blood to the kidney and preserving its function, as suggested by comparison of HF patients with an increased chloride concentration compared to those with a decreased chloride concentration.

\section{Worsening HF with Reduced Serum Chloride Concentration}

Worsening HF in association with a decrease in the serum chloride concentration (Fig. 1, right) leads to an inadequate distribution of chloride to the renal tubules, resulting in poor reabsorption of filtered sodium into the intravascular and interstitial spaces [20, 50, 52, 53], and thereby compromising blood vessel expansion or reducing plasma volume. In this subtype of worsening HF, activation of ADH and enhanced water retention would ensue in response to changes in the serum sodium and serum chloride levels in to ameliorate the arterial underfilling $[6,7]$. In addition, although overactivation of the RAAS might occur in response to the lower transfer of filtered chloride to the macula densa, it may be insufficient to enhance reabsorption of the filtered chloride and sodium solutes because of the reduced supply of chloride and sodium in the renal tubules of patients with worsening HF whose serum chloride concentration remains low. An insufficient accumulation of chloride in the serum leading to a reduced plasma volume may result from the low reabsorption of filtrated chloride and sodium solutes regardless of the increase in RAAS activity and the probable associated increase in sympathetic nervous system activity [2, 28]. Patients with this subtype of worsening HF present with a critical combination of vascular contraction, extravasation of vascular fluid into the interstitial space, increased peripheral arterial resistance, and reduced organ perfusion [60]. The clinical features of both this type of worsening HF and HF accompanied by low serum sodium levels $[61,62]$ would overlap.

\section{Causes of Disturbances in the Serum Chloride Concentration}

Diuretic treatment for various HF states is often accompanied by troublesome serum electrolyte disturbances. The mechanisms responsible for electrolyte disturbances in cardiovascular patients may be multifactorial and interrelated, resulting from neurohormonal activation, renal dysfunction, medications (particularly various diuretics and neurohormonal blockades), and dietary intake [63]. The origin of hypochloremia is likely similar to the putative etiology of hyponatremia in HF patients (i.e., low chloride results from either hemodilution or depletion due to loop diuretics) [64]. Importantly, enhanced activity of sympathetic nervous system and RAAS would be involved in the development of hypochloremia [48]; 1) bicarbonate resorption and chloride excretion in the proximal convoluted tubules under the stimulation of adrenaline and angiotensin II, and 2) induction of metabolic alkalosis by secretion of $\mathrm{H}^{+}$, bicarbonate gain, and excretion of chloride in the collecting ducts under aldosterone stimulation. This sophisticated concept of the relationship between hypochloremia and RAAS activity is conceivable, and is consistent with the 'chloride theory' for HF pathophysiology [18], as mentioned above.

\section{MECHANISM BY WHICH CHLORIDE REGULATES WATER DISTRIBUTION IN HF SYNDROME}

As already described, chloride likely has a central role in body fluid distribution in HF syndrome. What then are the possible underlying bio-chemical mechanisms of chloride for regulating water distribution in HF pathophysiology? To address this question, it is reasonable to consider the anatomy of the body fluid compartments, fluid exchange in the 
microcirculation, and the concept of the tonicity potential of chloride ions for movement of water across body fluid compartments.

\section{Body Fluid Compartments}

Body composition is approximately $60 \%$ water by weight, two-thirds (40\% water by weight) comprising the intracellular water compartment and the remaining one-third (20\% water by weight) comprising the extracellular water space $[55,56]$. The extracellular water space is further subdivided into five sub-compartments: (1) plasma volume; (2) interstitial and lymph fluid; (3) dense connective tissue, bone, and adipose tissues; (4) transcellular fluid within body cavities such as the pleural space, cerebrospinal fluid system, and peritoneal cavity; and (5) recirculating ductal secretion from the gastrointestinal tract $[55,56]$. The amount of body water in the plasma compartment (arterial and venous system) and interstitial/lymphatic compartment are $7 \%$ and $20 \%$ water by weight, respectively $[55,56]$.

Under HF pathophysiology, plasma volume in the arterial portion has an exceptionally important role for regulating body fluid status by way of aortic filling sensing and resultant RAAS and ADH responses, as summarized by the arterial underfilling (neurohormonal) hypothesis [6-9]. As described later, the fluid status of the vascular compartment is an important prognostic marker for $\mathrm{HF}$ pathophysiology $[35,36]$. Interstitial space, particularly dermal interstitial spaces, potentially contributes to fluid accumulation and the regulation of vascular volume from the outside space [56, 65-68]. A fluid shift or redistribution between compartments of the splanchnic vasculature and arterial space, in particular, should also be kept in mind for understanding and treating HF pathophysiology [69-71].

\section{Microcirculation: Plasma Filtration, Interstitial Fluid, and Lymphatic Drainage}

The old concept of microcirculation by the Starling principle is that transvascular exchange depends on a balance between hydrostatic and oncotic pressure gradients $[56,72,73]$. According to this principle, plasma fluid is filtrated to the interstitial space under a dominant hydrostatic pressure gradient at the arterial portion of capillaries, and thought to be absorbed back under a dominant colloidal osmotic pressure gradient at the venous end. New studies in this scientific field, however, have modified this classical concept because it is now established that much of the filtrated plasma fluid in the interstitial space returns to the circulation by way of the lymphatic system $[56,73,74]$ instead of through venous capillaries and venules. Therefore, excess filtrated plasma fluid is drained mainly by lymphatic pathways, allowing for limited fluid accumulation in the interstitial space. Once a critical lymphatic flow level is reached, the lymph flow cannot further increase and its ability to wash out interstitial proteins is impaired. Protein-rich edema is considered to compress lymphatic channels and increase compliance of the interstitial space, which facilitates the accumulation of edema [68]. Such a new microcirculation concept would be applicable to the HF pathophysiology.

Then, how are the transvascular solutes and water exchanged under HF pathophysiology? The recent concept of the 'revised Starling equation and the glycocalyx model' of transvascular fluid exchange states that the endothelial glycocalyx layer is semi-permeable with respect to anionic macromolecules such as albumin and other plasma proteins, and generates an effective oncotic gradient within a very small space $[73,75]$. This theory, however, does not take into account the anionic chloride ions in the mechanisms of fluid movement across the vascular and interstitial spaces under worsening $\mathrm{HF}$ or its resolution. Additional studies are required to determine whether the endothelial glycocalyx layer regulates the movement of anionic chloride ions, and if so, how such a mechanism regulates the movement of cationic sodium ions and water under an as yet unknown biochemical regulatory system for transvascular fluid exchange. 
Evidence Supporting the Actions of Chloride Ions Contributing to Water Distribution in the Body Fluid Compartments

In addition to the contribution of chloride to plasma volume regulation described above (see 'chloride theory' for HF pathophysiology), a recent clinical study [76] demonstrated that the pleural chloride concentration under worsening $\mathrm{HF}$ is high in comparison with the low chloride concentration (due to active transport of chloride ions out of the pleural space) in a normal physiologic state $[77,78]$, suggesting that chloride has an active role in the formation of pleural fluid. Under normal physiology, the chloride concentration in the interstitial space of the human body is high compared with the serum concentration $[49,55,56]$.

These facts suggest that water movement across body fluid compartments would definitely be regulated by changes in the chloride concentration in each body fluid compartment under normal physiology or under HF pathophysiology. Indeed, it is reported that active movement of chloride ions accompanies water secretion into the gastrointestinal tract under normal physiology $[37,51]$ or into the alveolar space under cardiogenic lung congestion [79]. Then, what is the biochemical contribution of chloride ions for regulating the distribution of water [18] in the human body?

\section{Tonicity (Effective Osmolality) Potential of Chloride Ions in the Human Body}

Solutes in the human body are classified as effective or ineffective osmoles on the basis of their ability to generate osmotic water movement, and osmotic water flux requires a solute concentration gradient [56]. 'Tonicity' is the effective osmolality across a barrier, and thus regulates free body water distribution to each body space compartment. At the capillary interface, small solutes of sodium, chloride, and potassium ions are considered to be fundamentally ineffective osmoles that freely move across the inter-endothelial spaces. In the human body, however, the concentration of sodium and chloride across vascular and interstitial spaces is in opposite directions, i.e., the sodium concentration is mildly low and chloride level is moderately high compared with their intra-vascular level [49]. Under HF pathophysiology, independently from other solutes, including sodium and albumin, chloride ions are positively associated with changes in the plasma volume $[15,17]$ and red blood cell volume [19] from stable to worsening HF and its resolution. Also, the formation of pleural effusion in worsening HF is deeply associated with chloride ions [76]. These clinical facts strongly suggest that chloride ions have the potential for regulating 'tonicity' in the human body, thus regulating the flow or distribution of free water across each body fluid compartment. How is it that chloride, and not sodium, has such a significant physiologic role for regulating water movement in HF syndrome? This may relate to the different biochemical characteristics between sodium, which has mainly an osmolality, and chloride, which has both osmolality and tonicity potentials, in the human body. Thus, sodium attracts water by its osmolality potential, and chloride not only attracts water by its osmolality potential but also regulates the distribution of water across body fluid compartments by its tonicity potential.

Besides the 'Donnan effect' via charged proteins for regulating fluid distribution [56, 80], the role of chloride for water distribution across body fluid compartments in the human body requires further investigation.

\section{VASCULAR AND ORGAN CONGESTION IN HF SYNDROME}

When considering fluid retention in clinical HF pathophysiology, it is important to evaluate fluid status particularly in the case of vascular and interstitial (tissue) congestion because the water distribution is heterogenous across body fluid compartments in individual HF patients $[66,68,81,82]$. Some reports also suggest different profiles of body fluid distribution between HF patients with preserved vs. reduced left ventricular ejection fraction [83], or HF patients with obesity [84]. The majority of HF 
patients would have a combination of intravascular congestion and tissue congestion, with one dominant phenotype. Differentiating and treating these two different forms of congestion specifically may improve the outcome. A diuretic strategy applied to each specific form of congestion, i.e., fluid accumulation in the intravascular space vs. interstitial space, would be achievable by manipulating the serum chloride concentration with suitable diuretic selection, as described later [85] (see the later section regarding diuretic treatment).

\section{Vascular Volume Overload: Burden on Cardiac Function}

Vascular congestion would strongly affect the clinical picture and course of HF. Plasma volume status could be estimated by ' $\%$ change in plasma volume' derived by the Strauss formula, i.e., relative changes in the plasma volume by two-point measurement of hemoglobin and hematocrit values during the HF clinical course $[9,17,35,86]$ or by the 'relative plasma volume status' calculated from weight and hematocrit, i.e., an index of the degree to which patients have deviated from their ideal plasma volume at some point in the HF clinical course [36, 87]. Many studies support an increased plasma volume as a critical ominous prognostic indicator in HF patients $[36,87,88]$. For example, Martens et al. [87] reported that even a slight plasma volume expansion ( $>0 \%$ increase above the 'ideal calculated' plasma volume) is associated with a higher risk for HF hospitalization and all-cause mortality in chronic HF patients. The importance of reducing the plasma volume in acute HF patients is supported by many clinical studies that have demonstrated a favorable clinical outcome after decongestive therapy and achievement of hemoconcentration [89-91].

\section{Organ (Interstitial/Tissue) Congestion: Burden to the Organ Function}

Vascular overload ensures cardiac burden and a vicious cycle of worsening of cardiac function, and concomitant organ congestion (tissue edema) impairs tissue oxygen and metabolic diffusion, distorts tissue architecture, obstructs capillary blood flow and lymphatic drainage, and then contributes to progressive organ dysfunction [92, 93]. The neurohormonal and inflammatory response to systemic congestion and/or peripheral hypoperfusion, if present, may further contribute to organ injury [93]. Neurohormones, oxidative stress, and inflammation may also impair the structure and function of the endothelial glycocalyx composed of glycosaminoglycan networks, leading to a loss of the interstitial buffer capacity and disproportional interstitial fluid accumulation [65-67] or an increased vascular resistance and endothelial dysfunction $[65,94]$. Indeed, freedom from congestion is associated with a good prognosis $[95,96]$. It is suggested that persistent signs of congestion in HF patients under diuretic treatment should be aggressively managed irrespective of the induction of the hemoconcentration $[91,97]$ and/or appearance of worsening renal function $[91,98]$. Furthermore, it is desirable to treat beyond the resolution of resting signs and symptoms of congestion to achieve a better clinical outcome [96].

\section{USE OF DIURETICS AND THEIR STANDARD CLASSIFICATION IN HF SYNDROME}

\section{Requirement of Diuretics for HF Patients}

The initiation of fluid retention in various HF states primarily originates from cardiac pump failure itself, and subsequent cardio-renal interactions [2] induce body fluid retention due to impaired renal sodium and water excretion secondary to neurohumoral upregulation [99]. Given the centrality of congestion to both the symptoms and outcomes of $\mathrm{HF}$, diuretics remain the cornerstone for the management of HF pathophysiology [100-102], including maintaining stable $\mathrm{HF}$ or treating acutely worsening HF. Also, the prognostic importance of the amelioration of vascular and tissue congestions is reported by many clinical studies as described above. Early initiation of furosemide 
treatment for acute HF patients would bring a good clinical outcome [103], and loop diuretic prescription for de novo HF patients at discharge ensure better 30-day clinical outcomes compared to those without prescription [104].

As described in the following working steps from upstream to downstream, the ideal cascades of decongestion by diuretic therapy for HF patients [105-107] are a continuous process of removing the extravasated fluid at the interstitial, lymphatic, and third spaces $[66,70,81]$ by the capillary and lymphatic systems, and pumping it out from the body via the cardiorenal system by: (1) draining or refilling the extravasated fluid into the capillaries by lowering the capillary oncotic pressure or enhancing tonicity by increasing the plasma solutes, particularly chloride ions, (2) centrally collecting the extra fluid from both the systemic and pulmonary circulation into the left-sided heart and pumping it to the kidney via the systemic artery system, (3) inducing adequate diuresis of extra body fluid in the kidney by glomerular and tubular functions, and finally, (4) regaining an individualized euvolemic status to retain adequate arterial and ventricular filling in relation to regaining optimal cardiac function and relieving venous congestion in each HF patient.

\section{Standard Diuretic Classification and Diuretic Strategy According to the HFS and ESC}

Approaches for treating congestion in $\mathrm{HF}$ depend on the type of fluid accumulation that is responsible for the worsening HF: vascular or cardiac type [66, 68-71]. Diuretics are recommended as first-line therapy for congested HF patients with good perfusion (i.e., 'wet and warm' HF status) as congestion likely results from the accumulation of fluid causing a volume overload. Diuretic therapy is the standard guideline-based strategy proposed by both the Heart Failure Society of America and European Society of Cardiology for patients with acute or chronic HF [101, 102]. Loop diuretics are most commonly prescribed (>90\%) for patients with acute HF. An appropriate thiazide or thiazidelike diuretic and/or mineralocorticoid receptor antagonist should be added to the pharmacologic repertoire for patients with acute HF $[101,102]$. The recommended dose escalation therapy based on 2.5 times the home dose for patients with acute HF is often accompanied by serum electrolyte disturbances already existing at the initial presentation and/or appearing during HF treatment [108]. A more thorough understanding of the 'chloride theory' of HF pathophysiology [15-18] would provide valuable insight and rational strategies for pharmacologic resolution of decongestion [85], as described below.

\section{PROPOSAL OF A NEW CLASSIFICATION AND PRACTICAL USE OF DIURETICS ACCORDING TO THE 'CHLORIDE THEORY'}

Because changes in the plasma volume are strongly associated with the serum chloride concentration [15-18] (Fig. 1), manipulation of the serum chloride concentration could become an attractive therapeutic target for HF treatment. Modulation of serum chloride using such treatments could induce not only a vascular volume change but also a fluid shift between the vascular and interstitial spaces. Thus, it is appropriate to specify the diuretic effects of each drug on the serum chloride concentration and newly construct a functional diuretic classification according to the 'chloride theory'.

\section{New Classification and Practical Use of Diuretics According to the 'Chloride Theory'}

A new diuretic classification is proposed on the basis of the effects of a diuretic on the serum chloride concentration, including diuretic effects at the nephron and on sodium and potassium electrolytes (Table 1) [85]. Loop/thiazide diuretics are potent chloride-depleting diuretics [46, 109-111]. Acetazolamide is a strong chloride-regaining diuretic [111, 112] mainly through its re-absorption of chloride in the nephron $[48,113,114]$. The aquaretic effect of acetazolamide might be involved in 
Table 1 Classification of diuretic agents according to their effects on the serum chloride concentration

\begin{tabular}{|c|c|c|c|c|c|c|c|c|}
\hline \multirow[t]{2}{*}{ Diuretic agent } & \multirow[t]{2}{*}{ Main mechanism } & \multicolumn{4}{|c|}{ Urinary excretion } & \multicolumn{3}{|c|}{$\begin{array}{l}\text { Serum } \\
\text { concentration }\end{array}$} \\
\hline & & $\overline{\mathrm{Cl}}$ & $\mathbf{N a}$ & $\mathbf{K}$ & Other & $\overline{\mathrm{Cl}}$ & $\mathrm{Na}$ & $\mathbf{K}$ \\
\hline \multicolumn{9}{|c|}{ A. Decreasing serum $C l$ concentration } \\
\hline 1. Loop diuretics & $\begin{array}{l}\text { Blocks sodium-potassium-chloride } \\
\text { cotransporter in thick ascending limb of the } \\
\text { loop of Henle }\end{array}$ & $\uparrow$ & $\uparrow$ & $\uparrow$ & & $\downarrow$ & $\downarrow$ & $\downarrow$ \\
\hline $\begin{array}{l}\text { 2. Thiazide } \\
\text { diuretics }\end{array}$ & $\begin{array}{l}\text { Blocks sodium-chloride cotransporter in the } \\
\text { distal convoluted tubule }\end{array}$ & $\uparrow$ & $\uparrow$ & $\uparrow$ & & $\downarrow$ & $\downarrow$ & $\downarrow$ \\
\hline \multicolumn{9}{|c|}{ B. Enhancing serum $\mathrm{Cl}$ concentration } \\
\hline $\begin{array}{l}1 . \\
\text { Acetazolamide }\end{array}$ & $\begin{array}{l}\text { Blocks carbonic anhydrase in the proximal } \\
\text { tubule }\end{array}$ & $\downarrow$ & $\uparrow$ & $\uparrow$ & $\begin{array}{l}\mathrm{HCO}_{3}^{-\uparrow} ; \\
\text { Water } \uparrow\end{array}$ & $\uparrow$ & $\uparrow \rightarrow$ & $\downarrow$ \\
\hline $\begin{array}{l}\text { 2. Aquaretic } \\
\text { diuretics }\end{array}$ & $\begin{array}{l}\text { Blocks vasopressin V2 receptor in the collecting } \\
\text { duct of the distal tubule }\end{array}$ & $\rightarrow$ & $\rightarrow$ & $\rightarrow$ & Water $\uparrow \uparrow$ & $\uparrow$ & $\uparrow$ & $\uparrow$ \\
\hline $\begin{array}{l}\text { 3. SGLT2 } \\
\text { inhibitor }\end{array}$ & $\begin{array}{l}\text { Blocks sodium-glucose cotransporter- } 2 \text { in the } \\
\text { proximal tubule }\end{array}$ & $\downarrow$ & $\uparrow \rightarrow$ & $\rightarrow$ & $\begin{array}{r}\text { Glucose } \uparrow ; \\
\text { Water } \uparrow\end{array}$ & $\uparrow$ & $\uparrow \rightarrow$ & $\rightarrow$ \\
\hline \multicolumn{9}{|c|}{ C. Neutral effect on serum $C l$ concentration } \\
\hline 1. MRA & $\begin{array}{l}\text { Antagonizes aldosterone receptor in the } \\
\text { collecting duct of the distal tubule }\end{array}$ & ? & $\uparrow$ & $\downarrow$ & $\begin{array}{l}\mathrm{H}^{+} \uparrow ; \\
\quad \mathrm{HCO}_{3}^{-} \uparrow\end{array}$ & $\rightarrow$ & $\downarrow$ & $\uparrow$ \\
\hline
\end{tabular}

$C l$ chloride, $K$ potassium, $M R A$ mineralocorticoid-receptor antagonists, $N a$ sodium, $S G L T 2$ sodium-glucose cotransporter-2

enhancing the serum chloride concentration $[115,116]$. Vasopressin receptor blockade would have a modest effect on enhancing the serum chloride concentration through its 'aquaretic' effect [109, 117]. The new glucose-lowering drug sodium-glucose cotransporter-2 inhibitor (SGLT2i) is likely to preserve or mildly enhance the serum chloride concentration $[109,118,119]$, potentially through aquaresis, aldosterone activation, and serum $\mathrm{HCO}_{3}{ }^{-}$concentration-decreasing effects [119]. Mineralocorticoid receptor antagonists would have a neutral effect on the serum chloride concentration [46]. The current classification and crude pharmacologic properties of diuretics will need to be revised and modified according to their effects on the serum chloride concentration to provide a more encompassing clinical description based on real-world pharmacologic studies.
Such a diuretic classification would allow for rational decision-making to achieve the ideal plasma volume and resolve congestive signs in parallel with maintaining a harmonic electrolyte balance. In general, the use of loop and thiazide diuretics can efficiently reduce the plasma volume by depleting serum chloride (Fig. 2, left half) [18], but it should be noted that induction of hypochloremia by these diuretics may induce resistance to these diuretics [12]. Removing the extravasated fluid from the interstitial and third spaces $[66,81,83]$ is also important toward reducing organ damage $[68,92,93]$, and this process could be effectively accomplished by enhancing the serum chloride concentration with the use of chloride-regaining diuretics, such as acetazolamide, vasopressin receptor antagonists, and SGLT2i (Fig. 2, right half) [18]. 


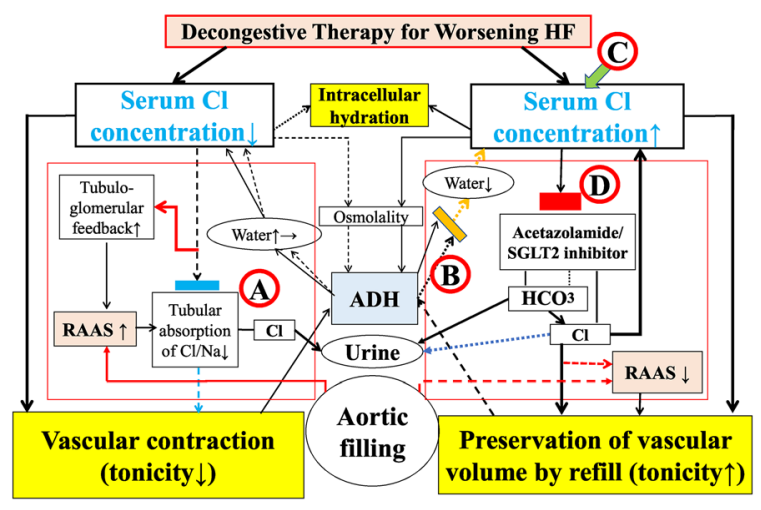

Fig. 2 Hypothesis of the 'chloride theory' underlying the therapeutic resolution of worsening heart failure; conventional diuretic therapy $(\mathbf{A}), \mathrm{V}_{2}$-receptor antagonist $(\mathbf{B}), \mathrm{Cl}$ supplementation (C), and acetazolamide (carbonic anhydrase inhibitor) or SGLT2i (D). Blue and yellow blocks represent inhibition of the absorption of $\mathrm{Cl} / \mathrm{Na}$ and water in each. The red block indicates the inhibitory action of carbonic anhydrase inhibitor or SGLT2i. Therapeutic effect induced by each treatment is shown by a solid or dotted line. The solid line indicates enhanced supply or excitatory effect and the dotted line indicates reduced supply or inhibitory effect. $\mathrm{ADH}$ antidiuretic hormone, $\mathrm{Cl}$ chloride, $\mathrm{HCO}_{3}{ }^{-}$bicarbonate, $\mathrm{HF}$ heart failure, $\mathrm{Na}$ sodium, RAAS renin-angiotensin-aldosterone system, $S G L T 2 i$ sodium-glucose cotransporter-2 inhibitor

\section{Suitable Monitoring Method for a Chloride-Centered Diuretic Strategy}

Clinical decisions regarding the HF status should be based on comprehensive evaluation of all HF-related symptoms, signs, and clinical tests because a single clinical symptom, sign, or test may lack sensitivity or specificity. Under the chloride-centered diuretic strategy [85], it is important to assess serial changes in the vascular volume and serum chloride concentration, and their interactions, as shown in Fig. 1 (worsening HF $[15,16,18]$ ) and Fig. 2 (decongestion $[17,18])$. Measurement of the estimated plasma volume $[35,36]$ or hemoglobin/hematocrit levels [91] is suitable for assessing changes in the intravascular volume in parallel with determining diuretic efficacy by monitoring changes in body weight to determine the amount of diuresis [120], serum b-type natriuretic peptide (BNP) level for reducing the cardiac burden [121], and other clinical tests for evaluating each component of HF presentation $[68,85,122,123]$.

\section{Adjunctive Therapy for a Chloride- Centered Diuretic Strategy for Treating HF Patients}

Diuretic therapy aimed at increasing plasma chloride levels can potentially cause residual cardiac volume overload, conferring a persistent cardiac burden. For example, diuresis to achieve body weight reduction is achieved by treatment with acetazolamide (chloride-retaining) and loop/thiazide diuretics (chloride-depleting), but while treatment with acetazolamide tends to preserve both plasma volume and kidney function, the magnitude of the serum BNP reduction, an objective measure of cardiac dysfunction, is small compared with that induced by treatment with loop/thiazide diuretics [111]. Other diuretics, such as vasopressin antagonists [117] and SGLT2i [124, 125] also do not adequately reduce serum BNP levels. The inadequate reduction of serum BNP levels by these diuretics may be explained by the 'chloride theory' [18]: while vasopressin receptor antagonist [29, 126] or SGLT2i [127] lead to the efficient removal of interstitial fluid, vascular volume-and thus, the residual burden on the heart-tends to be preserved. HF patients with persistent signs of cardiac burden following adequate diuretic therapy require additional treatments to reduce the cardiac burden and enhance cardiac power, such as inotropes, blood pressure and heart rate modulators, pacemaker implantation, and ultrafiltration $[106,107]$. The recently developed strategy to modulate the intrinsic heart rate by ivabradine [128] and/or empowerment of a biologically active natriuretic peptide system by an angiotensin receptor-neprilysin inhibitor (ARNI) $[31,129,130]$ might greatly improve the outcome and longevity of HF patients.

In patients with congestion due to vascular fluid redistribution, exhibiting hypertension but no weight gain, diuretics may be ineffective [69-71]. Congestion associated with worsening HF may occur due to both volume overload and volume redistribution, and it is important to 
differentiate between these two phenomena because of the differences in the therapeutic strategy. When volume redistribution is determined to be the underlying cause of the congestion, treatment must include vasodilatory agents rather than diuretics [71, 93, 101]. Diuretics activate RAAS [105, 131], possibly by their effects on the serum chloride dynamics and vascular volume. RAAS blockade enhances renal blood flow and decreases proximal tubular sodium reabsorption and is a first-line treatment for HF patients with dilutional hyponatremia [132, 133], which could include dilutional hypochloremia. In these cases, RAAS blockade should be prescribed in the absence of contraindications, including hypotension, renal dysfunction, and HF with a preserved ejection fraction $[100,134]$.

\section{OTHER CONCERNS: CHLORIDE AND CELLULAR HYDRATION IN HF SYNDROME}

The skeletal muscle is the predominant intracellular body fluid compartment (42\% water by weight), followed by the brain and viscera $(8 \%$ water by weight), and red blood cell compartments $(3.5 \%$ water by weight $)[55,56]$. The relation between chloride ions and cellular hydration status in the red blood cell and skeletal muscle compartments is briefly discussed below.

\section{Erythrocytes as an Intracellular Water Compartment}

Erythrocytes represent an ideal system for studying cellular water content $[135,136]$. The erythrocyte volume distribution in HF has been a subject of several clinical studies $[66,81,137,138]$. In untreated HF patients, the total red blood cell volume is reported to be only 5\% higher than that in controls [137]. Other studies $[66,81]$ have demonstrated that the distribution of red blood cell mass in patients admitted to the hospital for worsening $\mathrm{HF}$ is heterogenous, and may be reduced or increased. In HF status, the key serum electrolyte for regulating blood cell volume is reported to be chloride [19].

Cellular hydration is critical for cellular integrity [139, 140]. Cell volume is strictly controlled by the gain/loss of osmotically active solutes, including sodium, potassium, and chloride, or small organic molecules called organic osmolytes. In HF status, the key serum electrolyte for regulating blood cell volume is chloride [19]. Chloride, the most abundant anion in the body, is transported into erythrocytes [39, 49, 55]. In human red blood cells, volume regulation by electrolyte gain/loss is mediated by membrane transport pathways. The erythrocyte volume is regulated by the balance between potassium chloride and sodium chloride through the activation of separate potassium and chloride channels or $\mathrm{K}^{+} /$ $\mathrm{Cl}^{-}$cotransporters, which control the decreases in cell volume by the loss of potassium chloride [140]. Findings of a recent study reporting the effects of chloride on the red blood cell volume observed under different pathophysiologic states of HF [19] are consistent with the results of earlier studies indicating that chloride is a key electrolyte involved in regulating body water content.

\section{Muscle Tissue as an Intracellular Water Compartment}

Body fluid retention in the space in the total red blood cell volume is limited because of the presence of red blood cell membrane envelopes [55]. A remarkable amount of fluid ( 70\% water), however, is stored in the lean body mass, particularly the muscles [141]. Under changes in the HF status, fluids shift markedly between the intra- and extracellular spaces.

Few systematic studies have evaluated the fluid status of the whole-body muscle tissue in patients with HF, but many studies have measured the water and electrolyte content in muscle biopsy samples obtained from patients with HF [142-145]. In severe HF, both intracellular water and sodium contents increase [142-145], while the amount of potassium decreases [142, 145]. While little to no intracellular chloride is typically present in human 
skeletal muscle $[49,55]$, the chloride content in the muscle tissue increases under severe HF status [143-145]. Chloride freely distributes throughout the body according to the concentration gradient between intra- and extra-cellular water as a function of the transmembrane potential (Nernst equation) $[145,146]$. The mechanism(s) regulating the transmembrane diffusion of water and electrolytes, particularly chloride, in skeletal muscle under HF status are not yet clear and require detailed examination.

\section{FUTURE PERSPECTIVES}

As described in this review article, the electrolyte chloride has recently emerged as an important factor in the field of HF pathophysiology $[10,18,48,51]$. To determine the precise role of chloride in HF, several issues must be further evaluated in clinical, experimental, and molecular studies [147-151]. Firstly, how would modulation of the serum chloride concentration via suitable diuretic therapy affect the hemodynamics, neurohormonal status, and prognostics in HF patients? Second, loop/thiazide diuretic treatment often induces hypochloremia [109-111] and metabolic alkalosis, thus decreasing respiratory activity and enhancing carbon dioxide retention [152-154], resulting in a possible vicious cycle of worsening HF. Treating hypochloremia by chlorideregaining diuretics, i.e., acetazolamide $[111,112]$, aquaretic diuretic $[109,117]$, and SGLT2 inhibitors [109, 118, 119, 155, 156], might disrupt this vicious cycle via correcting the metabolic alkalosis. Further studies of the respiratory status in HF pathophysiology, including its relation to the electrolyte chloride, are also required [157-159]. Third, chloride ions are associated with the red blood cell-carrying capacity of carbon dioxide/bicarbonate, known as the 'chloride (Hamburger) shift' [37, 160], and oxygen unloading at the venous end of the capillaries in the tissue [51, 160]. How changes in the chloride dynamics affect blood gas turnover efficiency in HF pathophysiology remains unclear and should be investigated. Fourth, interstitial space potentially contributes to fluid accumulation and the regulation of vascular volume from the outside space [56, 65-68, 161, 162]. In particular, dermal interstitial space is reported to have an extensive depot of water-independent $\mathrm{Na}^{+}$storage, a capability of local regulatory mechanisms entailing glycosaminoglycans as the putative binding site, a buffering system for tonicity-dependent modulation via the skin lymphatic system, and a property that its disruption defines the hypertensive phenotype [163-166]. The extent of the contribution of electrolyte chloride to body fluid dynamics in the dermal interstitial space, however, is not known. Thus, it is necessary to explore whether or not chloride ions are meaningfully involved in such a mechanism in the dermal space. In addition to the issues described above, many other as-yet unknown aspects should be examined would exist in relation to the electrolyte chloride in HF pathophysiology.

\section{CONCLUSIONS}

Studies of HF pathophysiology according to the dynamics of chloride are rational because: (1) chloride is a key electrolyte for the renin-angiotensin-aldosterone system in the kidney, and (2) chloride is a possible regulatory electrolyte for body fluid distribution. The 'chloride theory' of HF pathophysiology provides valuable and rational strategies for HF treatment.

\section{ACKNOWLEDGEMENTS}

Funding. No funding or sponsorship was received for this study or for the publication of this article.

Authorship. All named authors meet the International Committee of Medical Journal Editors (ICMJ) criteria for authorship for this article, take responsibility for the integrity of the work as a whole, and have given their approval for this version to be published.

Disclosures. Hajime Kataoka has nothing to disclose. 
Compliance with Ethics Guidelines. This article is based on previously conducted studies and does not contain any new studies with human participants or animals performed by any of the authors.

Data Availability. Data sharing is not applicable to this article as no datasets were generated or analyzed during the current study.

Open Access. This article is licensed under a Creative Commons Attribution-NonCommercial 4.0 International License, which permits any non-commercial use, sharing, adaptation, distribution and reproduction in any medium or format, as long as you give appropriate credit to the original author(s) and the source, provide a link to the Creative Commons licence, and indicate if changes were made. The images or other third party material in this article are included in the article's Creative Commons licence, unless indicated otherwise in a credit line to the material. If material is not included in the article's Creative Commons licence and your intended use is not permitted by statutory regulation or exceeds the permitted use, you will need to obtain permission directly from the copyright holder. To view a copy of this licence, visit http://creativecommons.org/licenses/by$\mathrm{nc} / 4.0 /$.

\section{REFERENCES}

1. Gheorghiade M, Pang PS. Acute heart failure syndrome. J Am Coll Cardiol. 2009;53:557-73.

2. Rangaswami J, Bhalla V, Blair J, et al. Cardiorenal syndrome: classification, pathophysiology, diagnosis, and treatment strategies: a scientific statement from the American Heart Association. Circulation. 2019;139:e840-78.

3. Arrigo M, Jessup M, Mullens W, et al. Acute heart failure. Nat Rev. 2020;6:16.

4. Cody RJ, Covit AB, Schaer GL, Laragh JH, Sealey JE, Feldschuh J. Sodium and water balance in chronic congestive heart failure. J Clin Invest. 1986;77: 1441-52.

5. Volpe M, Tritto C, DeLuca N, et al. Abnormalities of sodium handling and of cardiovascular adaptations during high salt diet in patients with mild heart failure. Circulation. 1993;88(part 1):1620-7.

6. Schrier RW. Body fluid volume regulation in health and disease: a unifying hypothesis. Ann Intern Med. 1990;113:155-9.

7. Schrier RW, Fassett RG, Ohara M, Martin P-Y. Pathophysiology of renal fluid retention. Kidney Int. 1998;54(Suppl. 67):S127-32.

8. Cadnapaphornchai MA, Gurevich AK, Weinberger HD, Schrier RW. Pathophysiology of sodium and water relation in heart failure. Cardiology. 2001;96: 122-31.

9. Kalra PR, Anagnostopoulos C, Bolger AP, Coats AJS, Anker SD. The regulation and measurement of plasma volume in heart failure. J Am Coll Cardiol. 2002;39:1901-8.

10. Grodin JL, Simon J, Hachamovitch R, et al. Prognostic role of serum chloride levels in acute decompensated heart failure. J Am Coll Cardiol. 2015;66:659-66.

11. Grodin JL, Verbrugge FH, Ellis SG, Mullens W, Testani J, Tang WH. Importance of abnormal chloride homeostasis in stable chronic heart failure. Circ Heart Fail. 2016;9: e002453.

12. Hanberg JS, Rao V, ter Maaten JM, et al. Hypochloremia and diuretic resistance in heart failure: mechanistic insights. Circ Heart Fail. 2016;9: e003180.

13. Demissei BG, Valente MAE, Cleland JG, et al. Optimizing clinical use of biomarkers in high-risk acute heart failure patients. Eur J Heart Fail. 2016;18:269-80.

14. Testani JM, Hanberg JS, Arroyo JP, et al. Hypochloremia is strongly and independently associated with mortality in patients with chronic heart failure. Eur J Heart Fail. 2016;18:660-8.

15. Kataoka H. Vascular expansion during worsening of heart failure: effects on clinical features and its determinants. Int J Cardiol. 2017;230:556-61.

16. Kataoka H. Proposal for heart failure progression based on the 'chloride theory': worsening heart failure with increased vs. non-increased serum chloride concentration. ESC Heart Fail. 2017;4: 623-31.

17. Kataoka H. Biochemical determinants of changes in plasma volume after decongestion therapy for worsening heart failure. J Card Fail. 2019;25:213-7.

18. Kataoka H. The 'chloride theory', a unifying hypothesis for renal handling and body fluid 
distribution in heart failure pathophysiology. Med Hypotheses. 2017;104:170-3.

19. Kataoka H. Changes in red blood cell volume during transition of heart failure status: a reflection of cellular hydration status? Scand J Clin Lab Invest. 2018;78:305-11.

20. Kotchen TA, Luke RG, Ott CE, Galla JH, Whitescarver S. Effects of chloride on renal and blood pressure responses to sodium chloride. Ann Intern Med. 1983;98:817-22.

21. He X-R, Greenberg SG, Briggs JP, Schnermann J. Effects of furosemide and verapamil on the $\mathrm{NaCl}$ dependency of macula densa-mediated renin secretion. Hypertension. 1995;26:137-42.

22. Schnermann J. Juxtaglomerular cell complex in the regulation of renal salt excretion. Am J Physiol. 1998;274:R263-79.

23. Braunwald E. Heart failure. J Am Coll HF. 2013;1: $1-20$.

24. Guyton AC. Determination of cardiac output by equating venous return curves with cardiac response curves. Physiol Rev. 1955;35:123-9.

25. Forrester JS, Diamond G, Chatterjee K, Swan HJC. Medical therapy of acute myocardial infarction by application of hemodynamic subsets. N Engl J Med. 1976;295:1356-62.

26. Packer M. The neurohormonal hypothesis: a theory to explain the mechanism of disease progression in heart failure. J Am Coll Cardiol. 1992;20:248-54.

27. Cohn JN, Levine TB, Olivari MT, et al. Plasma norepinephrine as a guide to prognosis in patients with chronic congestive heart failure. N Engl J Med. 1984;311:819-23.

28. Triposkiadis F, Karayannis G, Giamouzis G, Skoularigis J, Louridas G, Butler J. The sympathetic nervous system in heart failure: physiology, pathophysiology, and clinical implications. J Am Coll Cardiol. 2009;54:1747-62.

29. Goldsmith SR, Gheorghiade M. Vasopressin antagonism in heart failure. J Am Coll Cardiol. 2005;46: 1785-91.

30. Lanfear DE, Sabbah HN, Goldsmith SR, et al. Association of arginine vasopressin levels with outcomes and the effect of V2 blockade in patients hospitalized for heart failure with reduced ejection fraction: insights from the EVEREST trial. Circ Heart Fail. 2013;6:47-52.

31. Volpe M, Carnovali M, Mastromarino V. The natriuretic peptides system in the pathophysiology of heart failure: from molecular basis to treatment. Clin Sci. 2016;130:57-77.

32. The CONSENSUS trial study group. Effects of enalapril on mortality in severe congestive heart failure: results of the cooperative north Scandinavian enalapril survival study (CONSENSUS). N Engl L Med. 1987;316:1429-35.

33. Packer M, Coats AJS, Fowler MB, et al. Effect of carvedilol on survival in severe chronic heart failure. N Engl J Med. 2001;344:1651-8.

34. Ponikowski P, Voors AA, Anker SD, et al. 2016 ESC Guidelines for the diagnosis and treatment of acute and chronic heart failure: the Task Force for the diagnosis and treatment of acute and chronic heart failure of the European Society of Cardiology (ESC): developed with the special contribution of the Heart Failure Association (HFA) of the ESC. Eur J Heart Fail. 2016;18:891-975.

35. Duarte K, Monnez J-M, Albuisson E, Pitt B, Zannad F, Rossignol P. Prognostic value of estimated plasma volume in heart failure. JACC Heart Fail. 2015;3: 886-93.

36. Ling HZ, Flint J, Damgaard $M$, et al. Calculated plasma volume status and prognosis in chronic heart failure. Eur J Heart Fail. 2015;17:35-43.

37. Berend K, van Hulsteijn LH, Gans ROB. Chloride: the queen of electrolytes? Eur J Intern Med. 2012;23:203-11.

38. O'Connor CM, Ahmad T. The role of sodium and chloride in heart failure: does it take two to tango? J Am Coll Cardiol. 2015;66:667-9.

39. De Bacquer D, De Backer G, De Buyzere M, Kornitzer M. Is low serum chloride level a risk factor for cardiovascular mortality? J Cardiovasc Risk. 1998;5: 177-84.

40. McCallum L, Jeemon P, Hastie CE, et al. Serum chloride is an independent predictor of mortality in hypertensive patients. Hypertension. 2013;62: 836-43.

41. Felker GM, Allen LA, Pocock SJ, et al. Red cell distribution width as a novel prognostic marker in heart failure: data from the CHARM program and the Duke databank. J Am Coll Cardiol. 2007;50: $40-7$.

42. Ferreira JP, Girerd N, Duarte K, et al. Serum chloride and sodium interplay in patients with acute myocardial infarction and heart failure with reduced ejection fraction: an analysis from the High-Risk Myocardial Infarction Database Initiative. Circ Heart Fail. 2017;10: e003500. 
43. Yamaguchi S, Abe M, Iseki K, et al. Prognostic impact of early changes in serum chloride concentrations among hospitalized acute heart failure patients: a retrospective cohort study. Circ Rep. 2020;2:409-19.

44. Cuthbert JJ, Pellicori P, Rigby A, et al. Low serum chloride in patients with chronic heart failure: clinical associations and prognostic significance. Eur J Heart Fail. 2018;20:1426-35.

45. Kondo T, Yamada T, Tamaki S, et al. Serial change in serum chloride during hospitalization could predict heart failure death in acute decompensated heart failure patients. Circ J. 2018;82:1041-50.

46. Grodin JL, Testani JM, Pandey A, et al. Perturbations in serum chloride homeostasis in heart failure with preserved ejection fraction: insights from TOPCAT. Eur J Heart Fail. 2018;20:1436-43.

47. Food and Nutrition Board, Institute of Medicine of the National Academies. Dietary Reference intakes for water, potassium, sodium, chloride, and sulfate. Washington: National Academies Press; 2004.

48. Cuthbert JJ, Bhandari S, Clark AL. Hypochloraemia in patients with heart failure: causes and consequences. Cardiol Ther. 2020;9:333-47.

49. Yunos NM, Bellomo R, Story D, Kellum J. Bench-tobedside review: chloride in critical illness. Crit Care. 2010;14:226.

50. McCallum L, Lip S, Padmanabhan S. The hidden hand of chloride in hypertension. Eur J Physiol. 2015;467:595-603.

51. Pfortmueller CA, Uehlinger D, von Haehling S, Schefold JC. Serum chloride levels in critical illness: the hidden story. Intensive Care Med Exp. 2018;6: 10 .

52. Shore AC, Markandu ND, MacGregor GA. A randomized crossover study to compare the blood pressure response to sodium loading with and without chloride in patients with essential hypertension. J Hypertension. 1988;6:613-7.

53. Boegehold MA, Kotchen TA. Importance of dietary chloride for salt sensitivity of blood pressure. Hypertension. 1991;17(suppl I):158-61.

54. Kataoka H. Rational of the 'chloride theory' as an explanation for neurohormonal activity in heart failure pathophysiology: literature review. J Clin Exp Cardiolog. 2019;10:634.

55. Edelman IS, Leibman J. Anatomy of body water and electrolytes. Am J Med. 1959;27:256-77.
56. Bhave G, Neilson EG. Body fluid dynamics: back to the future. J Am Soc Nephrol. 2011;22:2166-81.

57. Grodin JL, Mullens W, Dupont M, et al. Hemodynamic determinants of serum chloride in ambulatory patients with advanced heart failure. (abstr). J Am Coll Cardiol. 2016;67(suppl 5):1322.

58. Kataoka H. Clinical significance of spot urinary chloride concentration measurements in patients with acute heart failure: investigation on the basis of the 'tubulo-glomerular feedback' mechanism. Cardio Open. 2021;6:123-31.

59. Kataoka H. Plasma renin activity after diuretic treatment in patients with stable heart failure: with special reference to its association with electrolyte chloride. Cardio Open. 2021;6:132-42.

60. Benedict CR, Johnstone DE, Weiner DH, et al. Relation of neurohumoral activation to clinical variables and degree of ventricular dysfunction: a report from the registry of Studies of Left Ventricular Dysfunction. J Am Coll Cardiol. 1994;23: 1410-20.

61. Sica DA. Hyponatremia and heart failure: pathophysiology and implications. Cong Heart Fail. 2005;11:274-7.

62. Gheorghiade M, Rossi JS, Cotts W, et al. Characterization and prognostic value of persistent hyponatremia in patients with severe heart failure in the ESCAPE trial. Arch Intern Med. 2007;167: 1998-2005.

63. Grodin JL. Pharmacologic approaches to electrolyte abnormalities in heart failure. Curr Heart Fail Rep. 2016;13:181-9.

64. Verbrugge FH, Steels P, Grieten L, Nijst P, Tang WH, Mullens W. Hyponatremia in acute decompensated heart failure: depletion versus dilution. J Am Coll Cardiol. 2015;65:480-92.

65. Nijst P, Verbrugge FH, Grieten L, Dupont M, Steels $\mathrm{P}$, Tang WHW, Mullens W. The pathophysiological role of interstitial sodium in heart failure. J Am Coll Cardiol. 2015;65:3783-8.

66. Miller WL. Fluid volume overload and congestion in heart failure: time to reconsider pathophysiology and how volume is assessed. Circ Heart Fail. 2016;9: e002922.

67. Nijst $P$, Olinevich $M$, Hilkens $P$, et al. Dermal interstitial alterations in patients with heart failure and reduced ejection fraction. Circ Heart Fail. 2018;11: e004763.

68. Boorsma EM, ter Maaten JM, Damman K, et al. Congestion in heart failure: a contemporary look at 
physiology, diagnosis and treatment. Nat Rev Cardiol. 2020;17:641-55.

69. Gelman S. Venous function and central venous pressure: a physiologic story. Anesthesiology. 2008;108:735-48.

70. Fallick C, Sobotka PA, Dunlap ME. Sympathetically mediated changes in capacitance: redistribution of the venous reservoir as a cause of decompensation. Circ Heart Fail. 2011;4:669-75.

71. Fundim M, Hernandez AF, Felker M. Role of volume redistribution in the congestion of heart failure. J Am Heart Assoc. 2017;6: e006817.

72. Starling EH. On the absorption of fluid from the connective tissue spaces. J Physiol. 1896;19:312-26.

73. Woodcock TE, Woodcock TM. Revised Starling equation and the glycocalyx model of transvascular fluid exchange: an improved paradigm for prescribing intravenous fluid therapy. Br J Anaesth. 2012;108:384-94.

74. Reed RK, Rubin K. Transcapillary exchange: role and importance of the interstitial fluid pressure and the extracellular matrix. Cardiovasc Res. 2010;87: 211-7.

75. Levick JR, Michel CC. Microvascular fluid exchange and the revised Starling principle. Cardiovasc Res. 2010;87:198-210.

76. Kataoka H. Effusion-serum chloride gradient in heart failure-associated pleural effusion: pathophysiologic implications. Circ Rep. 2020;2:357-63.

77. Sahn St A, Willcox ML, Good JT Jr, Potts DE, Filley GF. Characteristics of normal rabbit pleural fluid: physiologic and biochemical implications. Lung. 1979;156:63-9.

78. Zocchi L, Agostoni E, Cremaschi D. Electrolyte transport across the pleura of rabbits. Resp Physiol. 1991;86:125-38.

79. Solymosi EA, Kaestle-Gembardt SM, Vadász I, et al. Chloride transport-driven alveolar fluid secretion is a major contributor to cardiogenic lung edema. Proc Natl Acad Sci USA. 2013;110:E2308-16.

80. Philipse A, Vrij A. The Donnan equilibrium: i. on the thermodynamic foundation of the Donnan equation of state. J Phys. 2011;23: 194106.

81. Miller WL, Mullan BP. Understanding the heterogeneity in volume overload and fluid distribution in decompensated heart failure is key to optimal volume management: role for blood volume quantitation. JACC Heart Fail. 2014;2:298-305.
82. Nijst P, Verbrugge FH, Bertrand PB, et al. Plasma volume is normal but heterogeneously distributed, and true anemia is highly prevalent in patients with stable heart failure. J Card Fail. 2017;23:138-44.

83. Miller WL, Mullan BP. Volume overload profiles in patients with preserved and reduced ejection fraction chronic heart failure: are there differences? A pilot study. JACC Heart Fail. 2016;4:453-9.

84. Miller WL, Borlaug BA. Impact of obesity on volume status in patients with ambulatory chronic heart failure. J Card Fail. 2020;26:112-7.

85. Kataoka H. Proposal for new classification and practical use of diuretics according to their effects on the serum chloride concentration: rationale based on the 'chloride theory.' Cardiol Ther. 2020;9:227-44.

86. Strauss MB, Davis RK, Rosenbaum JD, Rossmeisl EC. Water diuresis produced during recumbency by the intravenous infusion of isotonic saline solution. J Clin Invest. 1951;30:862-8.

87. Martens P, Nijst P, Dupont M, Mullens W. The optimal plasma volume status in heart failure in relation to clinical outcome. J Card Fail. 2019;25: 240-8.

88. Androne AS, Hryniewicz K, Hudaihed A, Mancini D, Lamanca J, Katz SD. Relation of unrecognized hypervolemia in chronic heart failure to clinical status, hemodynamics, and patient outcome. Am J Cardiol. 2004;93:1254-9.

89. van der Meer P, Postmus D, Ponikowski $P$, et al. The predictive value of short-term changes in hemoglobin concentration in patients presenting with acute decompensated heart failure. J Am Coll Cardiol. 2013;61:1973-81.

90. Testani JM, Brisco MA, Chen J, McCauley BD, Parikh CR, Tang WH. Timing of hemoconcentration during treatment of acute decompensated heart failure and subsequent survival: importance of sustained decongestion. J Am Coll Cardiol. 2013;62: 516-24.

91. Breidthardt T, Weidmann ZM, Twerenbold R, et al. Impact of haemoconcentration during acute heart failure therapy on mortality and its relationship with worsening renal function. Eur J Heart Fail. 2017;19:226-36.

92. Prowle JR, Echeverri JE, Liǵabo EV, Ronco C, Bellomo R. Fluid balance and acute kidney injury. Nat Rev Nephrol. 2010;6:107-15.

93. Harjola VP, Mullens W, Banaszewski M, et al. Organ dysfunction, injury and failure in acute heart failure: from pathophysiology to diagnosis and 
management: a review on behalf of the Acute Heart Failure Committee of the Heart Failure Association (HFA) of the European Society of Cardiology (ESC). Eur J Heart Fail. 2017;19:821-36.

94. Marti CN, Gheorghiade M, Kalogeropoulos AP, Georgiopoulou VV, Quyyumi AA, Butler J. Endothelial dysfunction, arterial stiffness, and heart failure. J Am Coll Cardiol. 2012;60:1455-69.

95. Lucas C, Johnson W, Hamilton MA, et al. Freedom from congestion predicts good survival despite previous class IV symptoms of heart failure. Am Heart J. 2000;140:840-7.

96. Ambrosy AP, Pang PS, Khan S, et al. Clinical course and predictive value of congestion during hospitalization in patients admitted for worsening signs and symptoms of heart failure with reduced ejection fraction: findings from the EVEREST trial. Eur Heart J. 2013;34:835-43.

97. Darawsha W, Chirmicci S, Solomonica A, et al. Discordance between hemoconcentration and clinical assessment of decongestion in acute heart failure. J Card Fail. 2016;22:680-8.

98. Metra M, Davison B, Bettari L, et al. Is worsening renal function an ominous prognostic sign in patients with acute heart failure? The role of congestion and its interaction with renal function. Circ Heart Fail. 2012;5:54-62.

99. Mullens W, Verbrugge FH, Nijst P, Tang WHW. Renal sodium avidity in heart failure: from pathophysiology to treatment strategies. Eur Heart J. 2017;38:1872-82.

100. Ellison DH, Felker GM. Diuretic treatment in heart failure. N Engl J Med. 2017;377:1964-75.

101. Mullens W, Damman K, Harjola VP, et al. The use of diuretics in heart failure with congestion: a position statement from the heart failure association of the European Society of Cardiology. Eur J Heart Fail. 2019;21:137-55.

102. Felker GM, Ellison DH, Mullens W, Cox ZL, Testani JM. Diuretic therapy for patients with heart failure: JACC state-of-the-art review. J Am Coll Cardiol. 2020;75:1178-95.

103. Matsue Y, Damman K, Voors AA, et al. Time-tofurosemide treatment and mortality in patients hospitalized with acute heart failure. J Am Coll Cardiol. 2017;69:3042-51.

104. Faselis C, Arundel C, Patel S, et al. Loop diuretic prescription and 30-day outcomes in older patients with heart failure. J Am Coll Cardiol. 2020;76: 669-79.
105. Verbrugge FH, Dupont M, Steels $\mathrm{P}$, et al. The kidney in congestive heart failure: 'are natriuresis, sodium, and diuretics really the good, the bad and the ugly?' Eur J Heart Fail. 2014;16:133-42.

106. von Lueder TG, Atar D, Krum H. Diuretic use in heart failure and outcomes. Clin Pharmacol Ther. 2013;94:490-8.

107. ter Maaten JM, Valente MAE, Damman K, Hillege HL, Navis G, Voors AA. Diuretic response in acute heart failure-pathophysiology, evaluation, and therapy. Nat Rev Cardiol. 2015;12:184-92.

108. Felker GM, Lee KL, Bull DA, et al. Diuretic strategies in patients with acute decompensated heart failure. N Engl J Med. 2011;364:797-805.

109. Tahara A, Kurosaki E, Yokono M, et al. Pharmacological profile of ipragliflozin (ASP1941), a novel selective SGLT2 inhibitor, in vitro and in vivo. Naunyn-Schmiedeberg's Arch Pharmacol. 2012;385:423-36.

110. Kataoka H. Dynamic changes in serum chloride concentrations during worsening of heart failure and its recovery following conventional diuretic therapy: a single center study. Health Sci Rep. 2018;1: e94.

111. Kataoka H. Comparison of changes in plasma volume and renal function between acetazolamide and conventional diuretics: understanding the mechanical differences according to the "chloride theory.' Cardiology. 2020;145:215-23.

112. Kataoka H. Acetazolamide as a potent chloride-regaining diuretic: short- and long-term effects, and its pharmacologic role under the 'chloride theory' for heart failure pathophysiology. Heart Vessels. 2019;34:1952-60.

113. Relman AS, Leaf A, Schwartz WB. Oral administration of a potent carbonic anhydrase inhibitor ('Diamox'). New Engl J Med. 1954;250:800-4.

114. Kataoka H. Treatment of hypochloremia with acetazolamide in an advanced heart failure patient and importance of monitoring urinary electrolytes. J Cardiol Cases. 2018;17:80-4.

115. Kataoka H. Vasopressin antagonist-like effect of acetazolamide in a heart failure patient: a case report. Eur Heart J Case Rep. 2018;2:1-5.

116. Kataoka H. Treatment of hyponatremia with acetazolamide in cardiovascular patients: possible alternative diuretic to vasopressin antagonists. Ann Cardiol Vasc Med. 2020;3:1032.

117. Kataoka H, Yamasaki Y. Strategy for monitoring decompensated heart failure treated by an oral 
vasopressin antagonist with special reference to the role of serum chloride: a case report. J Card Cases. 2016;14:185-8.

118. Masuda T, Watanabe Y, Fukuda K, et al. Unmasking a sustained negative effect of SGLT2 inhibition on body fluid volume in the rat. Am J Physiol Renal Physiol. 2018;315:F653-64.

119. Kataoka H, Yoshida Y. Enhancement of the serum chloride concentration by administration of sodium-glucose transporter-2 inhibitor and its mechanisms and clinical significance in type 2 diabetic patients: a pilot study. Diabetol Metab Syndr. 2020;12:5.

120. Valente MAE, Voors AA, Damman K, et al. Diuretic response in acute heart failure: clinical characteristics and prognostic significance. Eur Heart J. 2014;35:1284-93.

121. Dhaliwal AS, Deswal A, Pritchett A, et al. Reduction in BNP levels with treatment of decompensated heart failure and future clinical events. J Card Fail. 2009;15:293-9.

122. Harjola VP, Parissis J, Rocca HP, et al. Comprehensive in-hospital monitoring in acute heart failure: applications for clinical practice and future directions for research. A statement from the Acute Heart Failure Committee of the Heart Failure Association (HFA) of the European Society of Cardiology (ESC). Eur J Heart Fail. 2018;20:1081-99.

123. Girerd N, Seronde M-F, Coiro S, et al. Integrative assessment of congestion in heart failure throughout the patient journey. JACC Heart Fail. 2018;6: 273-85.

124. Nassif M, Windsor SL, Tang F, et al. Dapagliflozin effects on biomarkers, symptoms, and functional status in patients with heart failure with reduced ejection fraction: the DEFINE-HF trial. Circulation. 2019;140:1463-76.

125. Damman K, Beusekamp JC, Boorsma EM, et al. Randomized, double-blind, placebo-controlled, multicenter pilot study on the effects of empagliflozin on clinical outcomes in patients with acute decompensated heart failure (EMPA-RESPONSEAHF). Eur J Heart Fail. 2020;22:713-22.

126. Udelson JE, Orlandi C, Ouyang J, et al. Acute hemodynamic effects of tolvaptan, a vasopressin $V_{2}$ receptor blocker, in patients with symptomatic heart failure and systolic dysfunction: an international, multicenter, randomized, placebo-controlled trial. J Am Coll Cardiol. 2008;52:1540-5.

127. Hallow K, Helmlinger G, Greasly PJ, McMurray JJ, Boulton DW. Why do SGLT2 inhibitors reduce heart failure hospitalization?: a differential volume regulation hypothesis. Diabetes Obes Metab. 2018;20:479-87.

128. Swedberg K, Komajda M, Böhm M, et al. Ibabradine and outcomes in chronic heart failure (SHIFT): a randomised placebo-controlled study. Lancet. 2010;11:875-85.

129. D'Elia E, Iacovoni A, Vaduganathan M, Lorini FL, Perlini S, Senni M. Neprilysin inhibition in heart failure: mechanisms and substrates beyond modulating natriuretic peptides. Eur J Heart Fail. 2017;19: 710-7.

130. Docherty K, Vaduganathan M, Solomon SD, McMurray JJ. Sacubitril/Valsartan: neprilysin inhibition 5 years after PARADIGM-HF. JACC Heart Fail. 2020;8:800-10.

131. Mentz RJ, Stevens SR, DeVore AD, et al. Decongestion strategies and renin-angiotensin-aldosterone system activation in acute heart failure. JACC Heart Fail. 2015;3:97-107.

132. Dzau VJ, Colucci WS, Hollenberg NK, Williams GH. Relation of the renin-angiotensin-aldosterone system to clinical state in congestive heart failure. Circulation. 1981;63:645-51.

133. Lilly LS, Dzau VJ, Williams GH, Rydstedt L, Hollenberg NK. Hyponatremia in congestive heart failure: implications for neurohumoral activation and responses to orthostasis. J Clin Endocrinol Metab. 1984;59:924-30.

134. Schwartzenberg S, Redfield MM, From AM, Sorajja P, Nishimura RA, Borlaug BA. Effects of vasodilation in heart failure with preserved or reduced ejection fraction: implications of distinct pathophysiologies on response to therapy. J Am Coll Cardiol. 2012;59: 442-51.

135. Brugnara C. Erythrocyte membrane transport pathology. Curr Opin Hematol. 1997;4:122-7.

136. Bogner P, Sipos K, Ludány A, Somogyi B, Miseta A. Steady-state volumes and metabolism-independent osmotic adaptation in mammalian erythrocytes. Eur Biophys J. 2002;31:145-52.

137. Anand IS, Ferrari R, Kalra GS, Wahi PL, Pool-Wilson PA, Harris PC. Edema of cardiac origin: studies of body water and sodium, renal function, hemodynamic indexes, and plasma hormones in untreated congestive cardiac failure. Circulation. 1989;80: 299-305.

138. Ahlgrim C, Birkner P, Seiler F, et al. Increased red cell volume is a relevant contributing factor to an expanded blood volume in compensated systolic chronic heart failure. J Card Fail. 2020;26:420-8. 
139. McManus ML, Churchwell KB, Strange K. Regulation of cell volume in health and disease. New Engl J Med. 1995;333:1260-6.

140. Kurbannazarova RS, Bessonova SV, Okada Y, Sabirov RZ. Swelling-activated anion channels are essential for volume regulation of mouse thymocytes. Int J Mol Sci. 2011;12:9125-37.

141. Schoeller DA. Changes in total body water with age. Am J Clin Nutr. 1989;50:1176-81.

142. Mokotoff R, Ross G, Leiter L. The electrolyte content of skeletal muscle in congestive heart failure: a comparison of results with inulin and chloride as reference standards for extracellular water. J Clin Invest. 1952;31:291-9.

143. Talso PJ, Spafford N, Blaw M. The metabolism of water and electrolytes in congestive heart failure: II. The distribution of water and electrolytes in skeletal muscle in edematous patients with congestive failure before and after treatment. J Lab Clin Med. 1953;41:405-15.

144. Flear CTG, Crampton RF, Matthews DM. Observations on the electrolyte and water composition of skeletal muscle in patients in congestive cardiac failure, using in vitro method for determination of inulin space. Clin Sci. 1961;21:381-92.

145. Broqvist M, Dahlström U, Larsson J. Muscle water and electrolytes in severe chronic congestive heart failure before and after treatment with enalapril. Eur Heart J. 1992;13:243-50.

146. Eisenman AJ, MacKenzie LB, Peters JP. Protein and water of serum and cells of human blood, with a note on the measurement of red blood cell volume. J Biol Chem. 1936;116:33-45.

147. Veizis IE, Cotton CU. Role of kidney chloride channels in health and disease. Pediatr Nephrol. 2007;22:770-7.

148. Ponce-Coria J, San-Cristobal P, Kahle KT, et al. Regulation of NKCC2 by a chloride-sensing mechanism involving the WNK3 and SPAK kinases. Proc Natl Acad Sci USA. 2008;105:8458-63.

149. Cappola TP, Matkovich SJ, Wang W, et al. Loss-offunction DNA sequence variant in the CLCNKA chloride channel implies the cardio-renal axis in interindividual heart failure risk variation. Proc Natl Acad Sci USA. 2011;108:2456-61.

150. Hennings JC, Andrini O, Picard N, et al. The CLC-K2 chloride channel is critical for salt handling in the distal nephron. J Am Soc Nephrol. 2017;28:209-17.
151. Adkins GB, Curtis MJ. Potential role of cardiac chloride channels and transporters as novel therapeutic targets. Pharmacol Ther. 2015;145:67-75.

152. Jarboe TM, Penman RW, Luke RG. Ventilatory failure due to metabolic alkalosis. Chest. 1972;61: S61-3.

153. Tuller MA, Mehdi F. Compensatory hypoventilation and hypercapnia in primary metabolic alkalosis. Report of three cases. Am J Med. 1971;50: 281-90.

154. Alexander JK, West JR, Wood JA, Richards DW. Analysis of the respiratory response to carbon dioxide inhalation in varying clinical states of hypercapnia, anoxia, and acid-base derangement. J Clin Invest. 1955;34:511-32.

155. Kataoka H. Effects of SGLT2 inhibitor on neurohormonal activity and electrolyte management in an elderly patient with type 2 diabetes mellitus and acute heart failure: a case report. Ann Cardiol Vasc Med. 2020;3:1038.

156. Kataoka H. Favorable effect of sodium-glucose cotranspoter-2 inhibitor on respiratory function in type 2 diabetic patients. J Endocrine Dis Ther. 2020;1:5-9.

157. Kee K, Naughton MT. Heart failure and the lung. Circ J. 2010;74:2507-16.

158. Konishi M, Akiyama E, Suzuki H, et al. Hypercapnea in patients with acute heart failure. ESC Heart Fail. 2015;2:12-9.

159. Park JJ, Choi DJ, Yoon $\mathrm{CH}$, et al. The prognostic value of arterial blood gas analysis in high-risk acute heart failure patients: an analysis of the Korean Heart Failure (KorHF) registry. Eur J Heart Fail. 2015;17:601-11.

160. Thekkeveedu RK, Ramarao S, Dankhara N, Alur P. Hypochloremia secondary to diuretics in preterm infants: should clinicians pay close attention? Glob Pediatr Health. 2021;8:1-10.

161. Wiig H. Regulation of fluid volume from the outside: a role of glycosaminoglycans in the skin interstitium? Circ Heart Fail. 2018;11:E005135.

162. Benias PC, Wells RG, Sackey-Aboagye B, et al. Structure and distribution of an unrecognized interstitium in human tissues. Sci Rep. 2018;8:4947.

163. Machnik A, Neuhofer W, Jantsch J, et al. Macrophages regulate salt-dependent volume and blood pressure by a vascular endothelial growth factor-Cdependent buffering mechanism. Nat Med. 2009;15:545-52. 
164. Wiig H, Schröder A, Neuhofer W, et al. Immune cells control skin lymphatic electrolyte homeostasis and blood pressure. J Clin Invest. 2013;123: 2803-15.

165. Rossitto G, Touyz RM, Petrie MC, Delles C. Much Ado about $\mathrm{N}$... atrium: modelling tissue sodium as a highly sensitive marker of subclinical and localized edema. Clin Sci. 2018;132:2609-13.

166. Rossitto G, Mary S, McAllister C, et al. Reduced lymphatic reserve in heart failure with preserved ejection fraction. J Am Coll Cardiol. 2020;76: 2817-29. 